\title{
Ultrasound Assisted Synthesis of Gadolinium Oxide-Zeolitic Imidazolate Framework-8 Nanocomposites and Their Optimization for Photocatalytic Degradation of Methyl Orange Using Response Surface Methodology
}

\author{
Su-Gyeong Jeon ${ }^{1}$, Jeong-Won $\mathrm{Ko}^{2}$ and Weon-Bae Ko ${ }^{1,3, * \mathbb{D}}$ \\ 1 Department of Convergence Science, Graduate School, Sahmyook University, Seoul 01795, Korea; \\ kowb1@naver.com \\ 2 Department of Animal Life Resources, Sahmyook University, Seoul 01795, Korea; jwko7121@naver.com \\ 3 Department of Chemistry, Sahmyook University, Seoul 01795, Korea \\ * Correspondence: kowb@syu.ac.kr; Tel.: +82-02-3399-1700
}

Citation: Jeon, S.-G.; Ko, J.-W.; Ko, W.-B. Ultrasound Assisted Synthesis of Gadolinium Oxide-Zeolitic Imidazolate Framework-8

Nanocomposites and Their Optimization for Photocatalytic Degradation of Methyl Orange Using Response Surface Methodology. Catalysts 2021, 11, 1022. https:// doi.org/10.3390/catal11091022

Academic Editor: Ioannis Konstantinou

Received: 27 July 2021

Accepted: 21 August 2021

Published: 24 August 2021

Publisher's Note: MDPI stays neutral with regard to jurisdictional claims in published maps and institutional affiliations.

Copyright: (c) 2021 by the authors. Licensee MDPI, Basel, Switzerland. This article is an open access article distributed under the terms and conditions of the Creative Commons Attribution (CC BY) license (https:/ / creativecommons.org/licenses/by/ $4.0 /)$.

\begin{abstract}
An ultrasound-assisted method was used to prepare gadolinium oxide $\left(\mathrm{Gd}_{2} \mathrm{O}_{3}\right)$-zeolitic imidazolate framework (ZIF)-8 nanocomposites. The surface morphology, particle size, and properties of the $\mathrm{Gd}_{2} \mathrm{O}_{3}$-ZIF-8 nanocomposites were examined using scanning electron microscopy (SEM), X-ray diffraction (XRD), Raman spectroscopy, and ultraviolet-visible (UV-vis) spectroscopy. The synthesized $\mathrm{Gd}_{2} \mathrm{O}_{3}$-ZIF-8 nanocomposites were used as a catalyst to degrade methyl orange (MO) under UV light irradiation at $254 \mathrm{~nm}$. The color of the aqueous $\mathrm{MO}$ dye solution during photocatalytic degradation was examined using color spectroscopy. Response surface methodology (RSM) using a four-factor Box-Behnken design (BBD) was used to design the experiments and optimize the photocatalytic degradation of MO. The significance of the experimental factors and their interactions were determined using analysis of variance (ANOVA). The efficiency of $\mathrm{Gd}_{2} \mathrm{O}_{3}-\mathrm{ZIF}-8$ nanocomposites for the photocatalytic degradation of $\mathrm{MO}$ reached $98.05 \%$ within 40 min under UV irradiation at $254 \mathrm{~nm}$ under the experimental conditions of $\mathrm{pH} 3.3,0.4 \mathrm{~g} / \mathrm{L}$ catalyst dose, $0.0630 \mathrm{mM}$ $\mathrm{MO}$ concentration, and $431.79 \mathrm{mg} / \mathrm{L} \mathrm{H}_{2} \mathrm{O}_{2}$ concentration. The kinetics study showed that the $\mathrm{MO}$ photocatalytic degradation followed a pseudo-first-order reaction rate law.
\end{abstract}

Keywords: ultrasound-assisted method; $\mathrm{Gd}_{2} \mathrm{O}_{3}-\mathrm{ZIF}-8$ nanocomposites; photocatalytic degradation; methyl orange; response surface methodology

\section{Introduction}

Azo dyes make up more than half of the dyes produced globally, and anthraquinone dyes can be found abundantly [1]. Organic dyes are commonly released into wastewater. These dyes are hazardous to the environment if they are not destroyed and cause serious pollution [2]. Therefore, it is necessary to degrade such organic dye pollutants [3].

According to their raw materials, process principles, and pollutant characteristics, dye wastewater treatment methods can be classified into various categories, which include physical adsorption, membrane separation, biodegradation, electrochemical treatment, and photocatalysis [3]. The use of advanced oxidation processes (AOPs) is a major pathway for the near-ambient degradation of wastewater pollutants because the waste water pollutants can be degraded almost completely [4].

Photocatalytic degradation of organic dyes employed on metal oxide semiconductors has received a lot of interest in recent years. Owing to its good chemical durability, high thermal stability, and low phonon energy, $\mathrm{Gd}_{2} \mathrm{O}_{3}$ is a suitable semiconductor material for use as a photocatalyst [4]. It features a high refractive index and a suitable optical band gap, and is a potential candidate material for electronic and optoelectronic devices [4]. $\mathrm{Gd}_{2} \mathrm{O}_{3}$ is an n-type semiconductor that can be used as a photocatalyst to degrade organic pollutants 
in water [5]. However, for a single semiconductor, because the speed of the recombination of electrons and holes is fast, it leads to a decrease in the photocatalytic efficiency [6].

ZIF-8 is a type of metal organic framework (MOF) constructed from imidazolate organic ligands and $\mathrm{Zn}^{2+}$ metal ions. It exhibits higher thermal and chemical stability than other MOFs [7]. Owing to its structural features, pore cavities, and large surface area, ZIF-8 is desirable for many potential applications such as gas storage, membrane sieving separation, templating, catalysis, and sensing [7]. Therefore, the coupling of the semiconductor and the metal-organic framework is of great significance due to its porosity and large specific surface area [8]. The formation of hybrid composites between metal oxide semiconductors and MOFs has been shown to result in a synergistic effect in their photocatalytic performance $[9,10]$. Many studies have shown that metal oxideZIF-8 nanocomposites show better photocatalytic efficiency than the metal oxides and ZIF-8 alone [11]. $\mathrm{TiO}_{2} / \mathrm{ZIF}-8$ composites have been used to enhance the photocatalytic degradation of rhodamine B [12], while ZIF-8 and $\mathrm{ZnO}$ composites have been used to degrade $\mathrm{MO}$ under visible light [13]. The combined $\mathrm{SnO}_{2}$ and $\mathrm{ZIF}-8$ nanocomposites showed higher photocatalytic activity compared to a single-compound catalyst [14]. Herein, a composite photocatalyst was obtained by coupling $\mathrm{Gd}_{2} \mathrm{O}_{3}$ and $\mathrm{ZIF}-8$ via a simple method.

An ideal photocatalyst for dye degradation should have high light absorption efficiency, efficient electron-hole separation, and large surface area. The absorbed photons are used for degrading $\mathrm{MO}$ while a larger surface area of the photocatalyst provides more contact points between the photocatalyst and the $\mathrm{MO}$ dye and thereby leads to faster photocatalytic degradation.

Response surface methodology (RSM) quantifies the relationships between the controllable parameters and the obtained response surfaces. In RSM, the experimental data is fitted to a polynomial equation using statistical and mathematical analysis [15]. The interactions between the operating parameters can be estimated using a limited number of experiments [15]. The two most popular experimental design methods for RSM are the central composite design (CCD) and Box-Behnken design (BBD) [16-21]. In this study, we carried out both synthesis of hybrid $\mathrm{Gd}_{2} \mathrm{O}_{3}$-ZIF-8 nanocomposites using an ultrasound assisted method and an RSM experiment based on BBD to obtain optimum conditions for photocatalytic degradation of MO dye. In addition, a kinetics study was performed to evaluate the photocatalytic degradation rate of MO.

\section{Results and Discussion}

2.1. Identification of $\mathrm{Gd}_{2} \mathrm{O}_{3}$-ZIF-8 Nanocomposites and Color Test of MO Dye Solution

\subsubsection{XRD Diffraction}

The XRD results of hybrid $\mathrm{Gd}_{2} \mathrm{O}_{3}-\mathrm{ZiF}-8$ nanocomposites are shown in Figure 1 . The characteristic peaks of $\mathrm{Gd}_{2} \mathrm{O}_{3}$ nanowires and $\mathrm{ZiF}-8$ could be found in $\mathrm{Gd}_{2} \mathrm{O}_{3}-\mathrm{ZiF}-8$ nanocomposites. The XRD pattern in Figure 1 shows that $\mathrm{Gd}_{2} \mathrm{O}_{3}$ nanowires were observed at $2 \theta=20.14^{\circ}, 28.64^{\circ}, 33.16^{\circ}, 47.64^{\circ}$, and $56.53^{\circ}$, which correspond to the (211), (222), (400), (440), and (622) planes of the cubic phases (JCPDS 3-065-3181) [22]. The XRD peak values of ZIF-8 were observed at $2 \theta=7.30^{\circ}, 10.37^{\circ}, 12.70^{\circ}, 14.60^{\circ}, 16.43^{\circ}, 18.08^{\circ}$, and $22.15^{\circ}$, which correspond to the (011), (002), (112), (022), (013), (222), and (114) planes of the sodalite structure (JCPDS 00-062-1030) [23,24]. The crystallite size of the $\mathrm{Gd}_{2} \mathrm{O}_{3}$ nanowires in the synthesized $\mathrm{Gd}_{2} \mathrm{O}_{3}$-ZIF-8 nanocomposites was calculated using the Scherrer formula $[25,26]$.

$$
\mathrm{D}=K \lambda / \beta \cos \theta
$$

where $\mathrm{D}$ is the crystallite size, $K$ is the Scherrer constant, $\lambda$ is the $\mathrm{X}$-ray wavelength $(\mathrm{CuK} \alpha=0.15406 \mathrm{~nm}), \beta$ is the full width at half maximum intensity of the XRD peak in radians, and $\theta$ is the Bragg angle. The average crystallite size of the $\mathrm{Gd}_{2} \mathrm{O}_{3}$ nanowires at $28.64^{\circ}$ in the (222) plane was $22.14 \mathrm{~nm}$. 


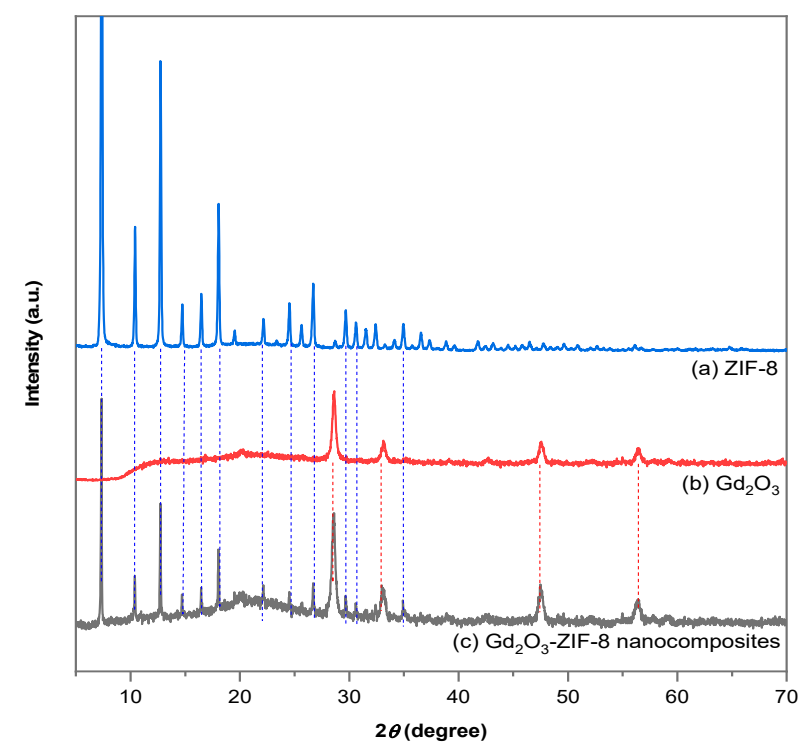

Figure 1. XRD patterns of synthesized (a) ZIF-8, (b) $\mathrm{Gd}_{2} \mathrm{O}_{3}$, and (c) $\mathrm{Gd}_{2} \mathrm{O}_{3}$-ZIF-8 nanocomposites.

\subsubsection{Raman Spectroscopy}

The Raman spectroscopy results of hybrid $\mathrm{Gd}_{2} \mathrm{O}_{3}-\mathrm{ZIF}-8$ nanocomposites show the prominent mode of $\mathrm{Gd}_{2} \mathrm{O}_{3}$ and major peaks of ZIF- 8 in Figure 2 and the Raman shift ranges from $200 \mathrm{~cm}^{-1}$ to $3500 \mathrm{~cm}^{-1}$. A peak corresponding to the $\mathrm{F}_{\mathrm{g}}+\mathrm{Ag}_{\mathrm{g}}$ mode of the $\mathrm{Gd}_{2} \mathrm{O}_{3}$ nanowires was observed at $358.41 \mathrm{~cm}^{-1}[22,26]$.

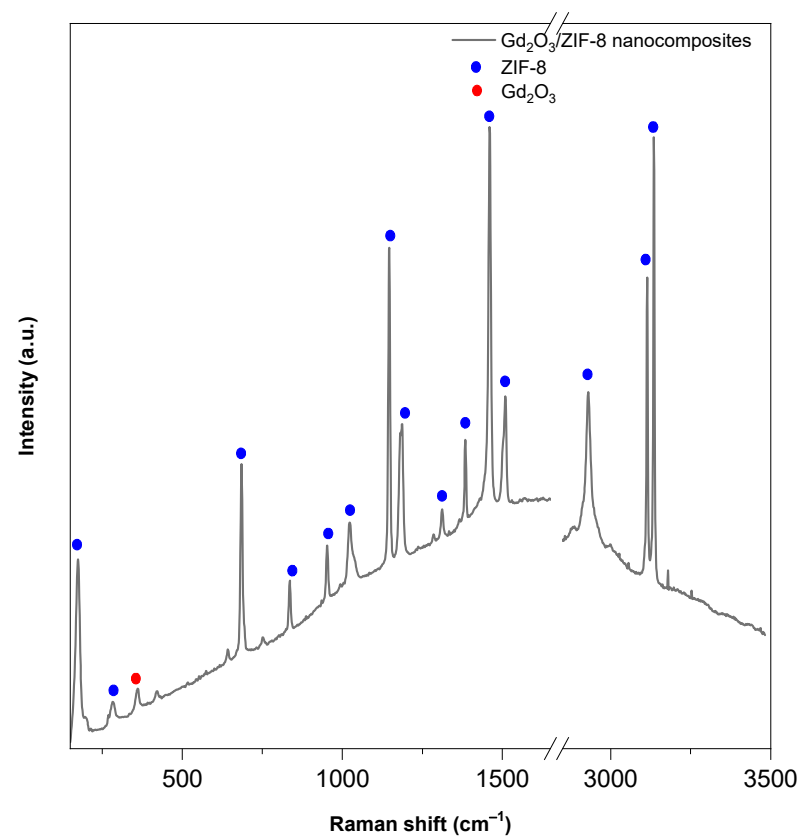

Figure 2. Raman spectra of the synthesized $\mathrm{Gd}_{2} \mathrm{O}_{3}$ - ZIF-8 nanocomposites.

The major peaks of ZIF-8 were observed at $282 \mathrm{~cm}^{-1}$ (Zn-N stretching), $684 \mathrm{~cm}^{-1}$ (imidazolium ring puckering), $825 \mathrm{~cm}^{-1}, 952 \mathrm{~cm}^{-1}, 1032 \mathrm{~cm}^{-1}$ (C-H bending), $1146 \mathrm{~cm}^{-1}$ (C-N stretching), $1180 \mathrm{~cm}^{-1}$ (C-N stretching $+\mathrm{N}-\mathrm{H}$ wag), $1186 \mathrm{~cm}^{-1}$ (C-N stretching), $1311 \mathrm{~cm}^{-1}$ (N-H wag), $1384 \mathrm{~cm}^{-1}\left(\mathrm{CH}_{3}\right.$ bending), $1460 \mathrm{~cm}^{-1}$ (C-H bending), $1509 \mathrm{~cm}^{-1}$ (C-C stretching), $2930 \mathrm{~cm}^{-1}$ (methyl C-H stretching), $3113 \mathrm{~cm}^{-1}$, and $3135 \mathrm{~cm}^{-1}$ (imidazolium ring $\mathrm{C}-\mathrm{H}$ stretching) $[27,28]$. 


\subsubsection{Scanning Electron Microscopy}

The SEM results of hybrid $\mathrm{Gd}_{2} \mathrm{O}_{3}$-ZIF-8 nanocomposites are shown in Figure 3. The SEM image of the $\mathrm{Gd}_{2} \mathrm{O}_{3}$ shows that it had an aggregated nanowire-like shape (Figure 3a). The nanowire-like shape of $\mathrm{Gd}_{2} \mathrm{O}_{3}$ was placed on the cubic-shaped ZIF-8 (Figure 3b,c).

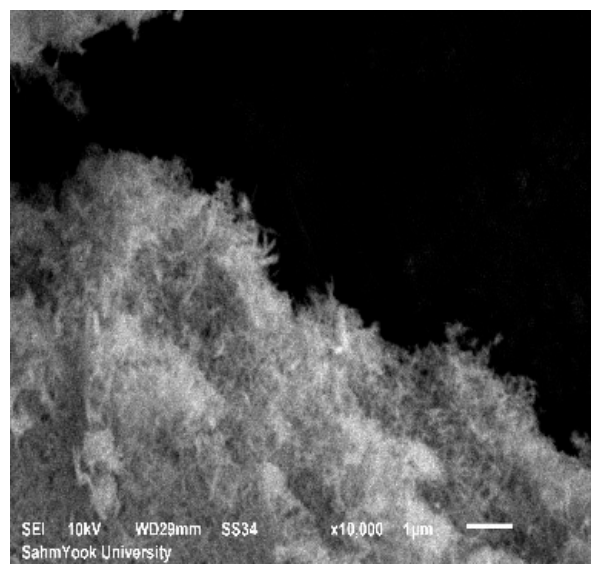

(a)

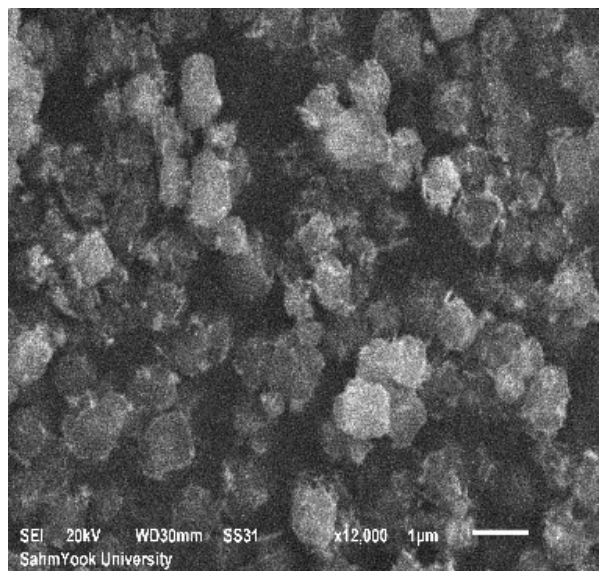

(c)

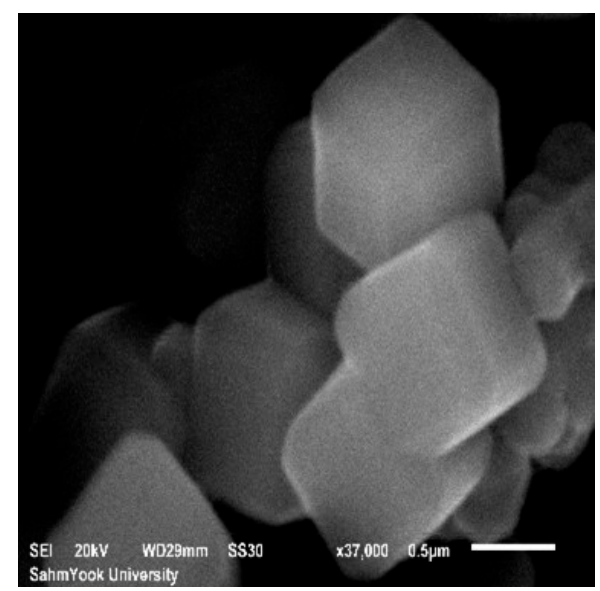

(b)

Figure 3. SEM images of (a) $\mathrm{Gd}_{2} \mathrm{O}_{3}$ nanowires, (b) ZIF-8, and (c) $\mathrm{Gd}_{2} \mathrm{O}_{3}$-ZIF-8 nanocomposites.

2.2. Investigation of Photocatalytic Activity for Degradation of $\mathrm{MO}$ using $\mathrm{Gd}_{2} \mathrm{O}_{3}-\mathrm{ZIF-8}$ Nanocomposites

The property of light absorption was measured to identify the absorption band of $\mathrm{Gd}_{2} \mathrm{O}_{3}$-ZIF-8 nanocomposites that corresponds to the light irradiation at $254 \mathrm{~nm}$ in Figure $\mathrm{S} 1$. The absorption peak of the $\mathrm{Gd}_{2} \mathrm{O}_{3}-\mathrm{ZIF}-8$ nanocomposites was observed at $208 \mathrm{~nm}$ in UV-vis spectroscopy in Figure S1a. The bandgap energy of $\mathrm{Gd}_{2} \mathrm{O}_{3}-\mathrm{ZIF}-8$ nanocomposites was evaluated to be $4.85 \mathrm{eV}$ in Figure S1b. Therefore, the photocatalyst of $\mathrm{Gd}_{2} \mathrm{O}_{3}-\mathrm{ZIF}-8$ nanocomposites could absorb light irradiation at $254 \mathrm{~nm}$.

Figure $4 \mathrm{a}$ shows the photocatalytic degradation of $\mathrm{MO}$ observed through UV-vis spectrophotometry at constant time intervals. The UV-vis spectrophotometry data confirms that the absorption peaks of the MO solution decreased with time. 


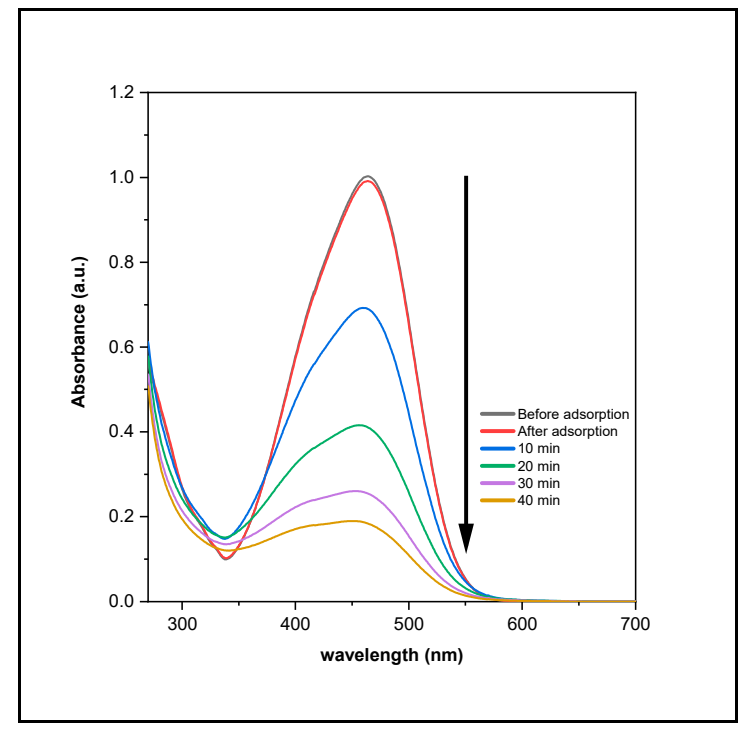

(a)

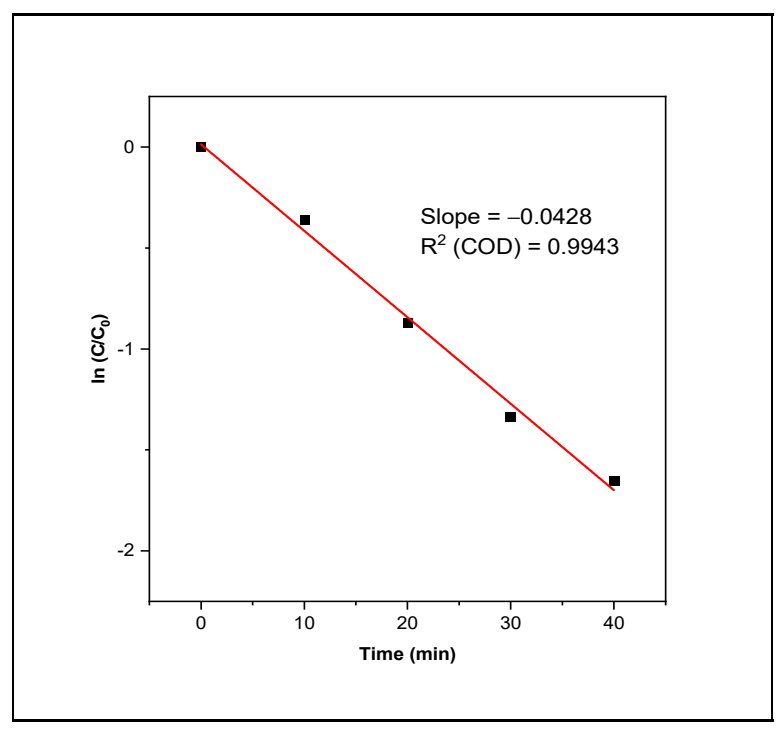

(b)

Figure 4. (a) UV-vis absorption spectra and (b) kinetics study of MO dye photocatalytic degradation.

Upon UV irradiation, the electrons in the valence band of the photocatalyst moved into the conduction band. This resulted in the continuous generation of holes $\left(\mathrm{h}^{+}\right)$in the valence band and electrons $\left(\mathrm{e}^{-}\right)$in the conduction band. The generation of electron-hole pairs contributed to the activity of the photocatalyst. Holes with high oxidative ability oxidized $\mathrm{OH}^{-}$ions into $\cdot \mathrm{OH}$ radicals in the aqueous $\mathrm{MO}$ solution. Valence band holes and conduction band electrons combined with hydroxide ions and oxygen to produce $\cdot \mathrm{OH}$ and $\cdot \mathrm{O}_{2}{ }^{-}$radicals. The $\cdot \mathrm{OH}$ and $\cdot \mathrm{O}_{2}{ }^{-}$radicals could act as oxidizing agents to the $\mathrm{MO}$ dye molecules $[4,5,29]$. The role of each component in the $\mathrm{Gd}_{2} \mathrm{O}_{3}$-ZIF- 8 nanocomposites is as a co-photocatalyst due to the enhanced rate of photocaltalytic degradation of $\mathrm{MO}$ when $\mathrm{Gd}_{2} \mathrm{O}_{3}$ and ZIF-8 are combined than when only $\mathrm{Gd}_{2} \mathrm{O}_{3}$ is alone $[6,26]$.

\subsection{Kinetics Study for Photocatalytic Degradation of $M O$}

To determine the photocatalytic kinetic model, the degradation of MO dye is examined with two kinetic models, including the first-order kinetic model and the second-order kinetic model, as expressed in the following equations. First-order kinetic model $[30,31]$ :

$$
\ln C_{\mathrm{t}}=-k_{1} t+\ln C_{0}
$$

Second-order kinetic model [32,33]:

$$
1 / C_{t}=-k_{2} t+1 / C_{0}
$$

where $C_{0}(\mathrm{mM})$ and $C_{t}(\mathrm{mM})$ are assigned as concentration of MO dyes at time $=0$ and time $=t\left(\mathrm{~min}^{-1}\right)$, respectively. $k_{1}\left(\mathrm{~min}^{-1}\right)$ and $k_{2}\left(\mathrm{~min}^{-1}\right)$ represent the rate constants of firstorder and second-order, respectively. Accordingly, the fitting results from experimental investigations into two distinct kinetic models are demonstrated in Figure S2, where higher $\mathrm{R}^{2}$ (0.9943) among the two examined models appears in the first-order kinetic model, validating the underlying kinetics for $\mathrm{MO}$ dye degradation under ultraviolet irradiation at $254 \mathrm{~nm}$.

The linear behavior of the curve confirms that the degradation of $\mathrm{MO}$ followed a pseudo-first-order reaction rate law as shown in Figure $4 \mathrm{~b}$ and the value of $\mathrm{R}^{2}$ (coefficient of determination) for the pseudo-first-order reaction kinetics was 0.9943 . 


\subsection{Color Test of Photocatalytic Degradation of MO Dye Solution}

The changes in $\Delta L, \Delta a, \Delta b$, and $\Delta E$ are listed in Table 1. The increase in $\Delta L$ indicates that the MO solution became whiter because of photocatalytic degradation. The negative values of $\Delta a$ and $\Delta b$ indicate that the MO solution tended to become less reddish owing to photocatalytic degradation. The total color change, $\Delta E$, indicates the color difference between two colors under UV light irradiation [34,35]. Before the color of the solution was measured by a color spectrophotometer, the solution was centrifuged for $1 \mathrm{~min}$ to remove the photocatalyst from the solution. Then, we measured the color of only liquid solution with a color spectrophotometer. Therefore, the aggregation of photocatalyst did not affect measuring the color of the solution. The color change of the MO photocatalytic degradation was measured within the range of 0 to 100 . Figure 5 shows the chromaticity diagram using the calculated $\mathrm{x}$ and $\mathrm{y}$ coordinates of a given color in the CIE 1931 color space. The color of the MO solution in the CIE1931 color space changed from red to green and from yellow to blue with increasing UV light exposure time because of photocatalytic degradation.

Table 1. Time-dependent color changes of $\mathrm{MO}$ solution using $\mathrm{Gd}_{2} \mathrm{O}_{3}-\mathrm{ZIF}-8$ nanocomposites as photocatalyst.

\begin{tabular}{ccccc}
\hline Times & $\boldsymbol{\Delta}$ & $\boldsymbol{\Delta} \boldsymbol{a}$ & $\boldsymbol{\Delta} \boldsymbol{b}$ & $\boldsymbol{\Delta} \boldsymbol{E}$ \\
\hline $0 \mathrm{~min}$ & 0 & 0 & 0 & 0 \\
$10 \mathrm{~min}$ & 8.73 & -7.8 & -22.68 & 25.52 \\
$20 \mathrm{~min}$ & 12.78 & -12.94 & -50.06 & 54.11 \\
$30 \mathrm{~min}$ & 15.7 & -13.06 & -67.06 & 70.10 \\
$40 \mathrm{~min}$ & 16.3 & -12.98 & -70.15 & 73.17 \\
\hline
\end{tabular}

\section{CIE 1931}

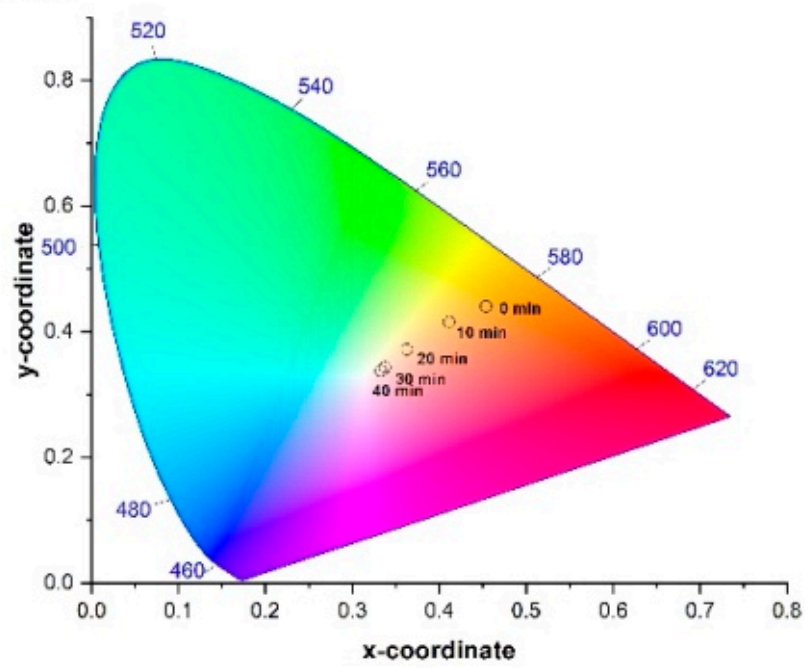

Figure 5. The CIE chromaticity diagram for photocatalytic degradation of $\mathrm{MO}$ using $\mathrm{Gd}_{2} \mathrm{O}_{3}$-ZIF-8 nanocomposites. 


\subsection{Box-Behnken Design with Response Surface Methodology (RSM)}

The photocatalytic degradation of $\mathrm{MO}$ using $\mathrm{Gd}_{2} \mathrm{O}_{3}-\mathrm{ZIF}-8$ nanocomposites is optimized by a four-factor and three-level BBD design consisting of 27 sets of experimental data for the optimization reactions, including replication at the center point $[25,36]$. Four independent variables, namely the initial $\mathrm{pH}\left(X_{1}\right)$, catalyst dose $\left(X_{2}\right)$, MO concentration $\left(X_{3}\right)$, and $\mathrm{H}_{2} \mathrm{O}_{2}$ concentration $\left(X_{4}\right)$, were assessed. The photocatalytic degradation efficiency of $\mathrm{MO}$ was used as the response variable $(Y)$. Table 2 shows the low $(-1)$, medium (0), and high $(+1)$ levels and the ranges of the independent variable parameters. The experimental data and response for the photocatalytic degradation of MO are shown in Table 3.

Table 2. Experimental design levels of chosen model parameters.

\begin{tabular}{cccccc}
\hline & & & \multicolumn{3}{c}{ Range and Levels } \\
\cline { 4 - 6 } $\begin{array}{c}\text { Independent } \\
\text { Variables }\end{array}$ & Unit & Symbol & Low (-1) & Medium (0) & High (+1) \\
\hline $\mathrm{pH}$ & - & $X_{1}$ & 3 & 5 & 7 \\
$\begin{array}{c}\text { Dose of catalyst } \\
\begin{array}{c}\text { Concentration of } \\
\text { methyl orange }\end{array}\end{array}$ & $\mathrm{g} / \mathrm{L}$ & $X_{2}$ & 0.1 & 0.3 & 0.5 \\
$\begin{array}{c}\text { Concentration of } \\
\mathrm{H}_{2} \mathrm{O}_{2}\end{array}$ & $\mathrm{mM}$ & $X_{3}$ & 0.0630 & 0.0840 & 0.1050 \\
\hline
\end{tabular}

Table 3. Experimental conditions of coded variables for the various runs of Box-Behnken design and the obtained experimental and predicted MO photocatalytic degradation percentages.

\begin{tabular}{|c|c|c|c|c|c|c|c|c|c|c|c|c|c|}
\hline \multirow[b]{2}{*}{ Run } & \multirow[b]{2}{*}{$X_{1}$} & \multirow[b]{2}{*}{$X_{2}$} & \multirow[b]{2}{*}{$X_{3}$} & \multirow[b]{2}{*}{$X_{4}$} & \multicolumn{2}{|c|}{ Degradation Percentage } & \multirow[b]{2}{*}{ Run } & \multirow[b]{2}{*}{$X_{1}$} & \multirow[b]{2}{*}{$X_{2}$} & \multirow[b]{2}{*}{$X_{3}$} & \multirow[b]{2}{*}{$X_{4}$} & \multicolumn{2}{|c|}{ Degradation Percentage } \\
\hline & & & & & Experimental & Predicted & & & & & & Experimental & Predicted \\
\hline 1 & 1 & 0 & 1 & 0 & 46.93 & 46.25 & 15 & 0 & 1 & 1 & 0 & 57.62 & 58.39 \\
\hline 2 & 0 & 0 & 0 & 0 & 64.76 & 64.46 & 16 & 0 & 0 & -1 & -1 & 52.22 & 51.45 \\
\hline 3 & 0 & 0 & 1 & -1 & 32.12 & 32.11 & 17 & -1 & 0 & -1 & 0 & 94.79 & 95.74 \\
\hline 4 & 0 & 0 & 1 & 1 & 48.63 & 49.06 & 18 & 0 & -1 & 0 & 1 & 44.80 & 44.43 \\
\hline 5 & 1 & 1 & 0 & 0 & 50.35 & 50.30 & 19 & 0 & 1 & 0 & -1 & 35.54 & 36.18 \\
\hline 6 & 0 & 1 & 0 & 1 & 59.59 & 58.78 & 20 & 0 & 0 & 0 & 0 & 63.72 & 64.46 \\
\hline 7 & 0 & -1 & -1 & 0 & 69.74 & 69.04 & 21 & 1 & 0 & -1 & 0 & 67.85 & 68.68 \\
\hline 8 & 0 & -1 & 1 & 0 & 43.85 & 43.89 & 22 & 0 & 1 & -1 & 0 & 76.03 & 76.07 \\
\hline 9 & -1 & -1 & 0 & 0 & 67.89 & 67.60 & 23 & -1 & 0 & 1 & 0 & 75.89 & 75.34 \\
\hline 10 & -1 & 0 & 0 & 1 & 78.78 & 79.54 & 24 & 1 & -1 & 0 & 0 & 45.98 & 46.24 \\
\hline 11 & -1 & 0 & 0 & -1 & 52.29 & 52.04 & 25 & -1 & 1 & 0 & 0 & 85.69 & 85.09 \\
\hline 12 & 0 & 0 & 0 & 0 & 64.90 & 64.46 & 26 & 0 & -1 & 0 & -1 & 27.91 & 28.99 \\
\hline 13 & 1 & 0 & 0 & 1 & 42.66 & 42.98 & 27 & 0 & 0 & -1 & 1 & 72.88 & 72.55 \\
\hline 14 & 1 & 0 & 0 & -1 & 33.12 & 32.44 & - & - & - & - & - & - & - \\
\hline
\end{tabular}

\subsubsection{Effect of $\mathrm{pH}$}

In Figure 6a, the effect of $\mathrm{pH}$ was investigated by varying only the $\mathrm{pH}$ from 3 to 7 while the other conditions remained the same. Under acidic conditions, the MO was negatively charged, and the photocatalyst surface positively charged [29]. Electrostatic attraction occurred between the $\mathrm{MO}$ and the photocatalyst. The transformation of the MO dye molecules to $\mathrm{CO}_{2}$ and $\mathrm{H}_{2} \mathrm{O}$ under radical attack in the photocatalytic reaction was attributed to electrostatic attraction $[37,38]$. 


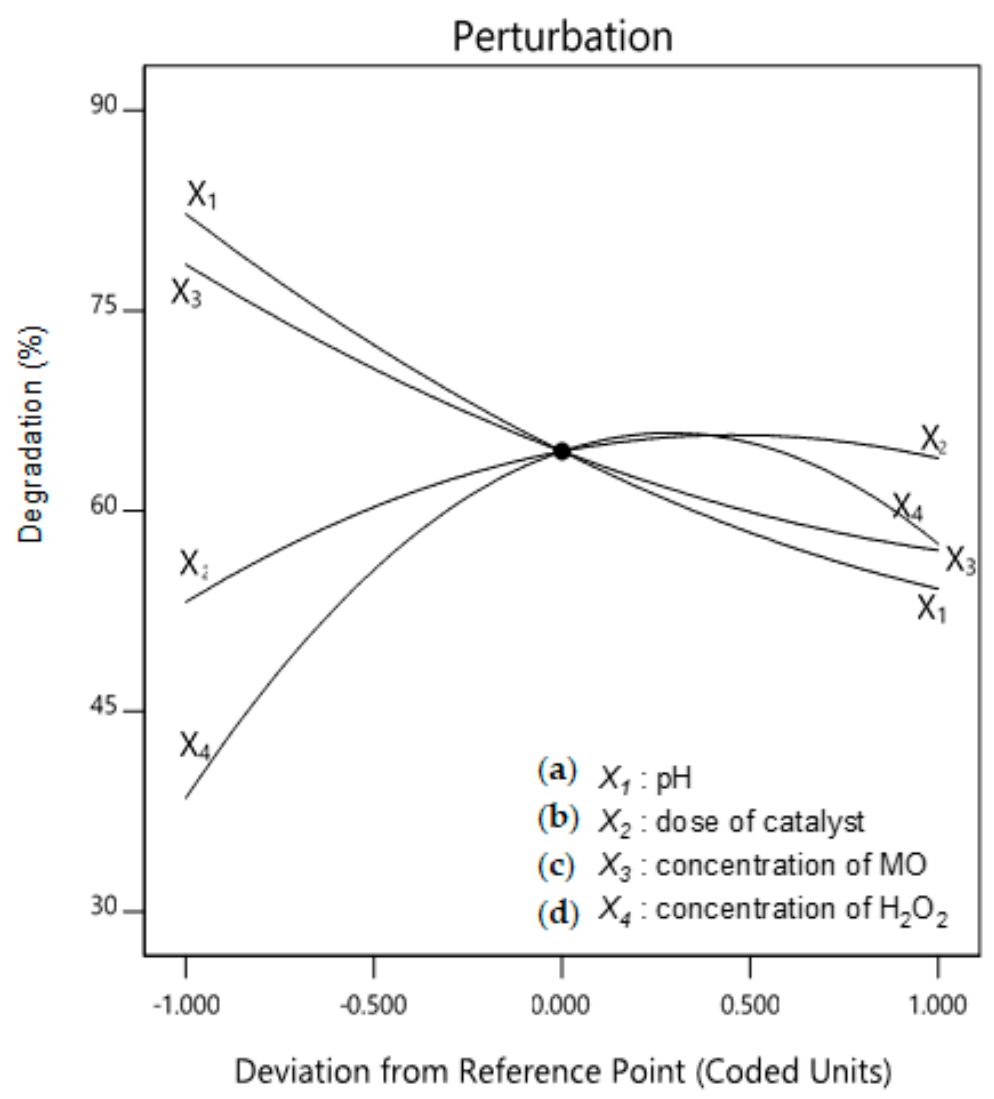

Figure 6. The variation of the deviation from the reference point for photocatalytic degradation using $\mathrm{Gd}_{2} \mathrm{O}_{3}$-ZIF-8 nanocomposites with (a) $\mathrm{X}_{1}: \mathrm{pH}$, (b) $\mathrm{X}_{2}$ : dose of catalyst, (c) $\mathrm{X}_{3}$ : concentration of $\mathrm{MO}$, and (d) $\mathrm{X}_{4}$ : concentration of $\mathrm{H}_{2} \mathrm{O}_{2}$.

\subsubsection{Effect of Photocatalyst Concentration}

In Figure $6 \mathrm{~b}$, the effect of the photocatalyst concentration was investigated by varying only the photocatalyst dose from $0.1 \mathrm{~g} / \mathrm{L}$ to $0.3 \mathrm{~g} / \mathrm{L}$ while the other conditions remained the same. Increasing the concentration of the photocatalyst in the MO solution may decrease the transmission of light [3]. Therefore, excess photocatalyst in solution could interfere with the photocatalytic degradation of the MO solution [36].

\subsubsection{Effect of MO Concentration}

After $40 \mathrm{~min}$, the $\mathrm{MO}$ photocatalytic degradation efficiency decreased when the $\mathrm{MO}$ concentration increased from 0.0630 to $0.0105 \mathrm{mM}$ (Figure 6c). Within the experimental range, the pseudo-first-order rate constant $k_{1}$ decreased with an increase in the $\mathrm{MO}$ concentration based on Equation (10) [3]. These results indicate that the absorption of light on the photocatalyst surface decreased at higher concentrations. Moreover, the photocatalytic degradation of $\mathrm{MO}$ occurred on the surface of the active sites of the photocatalyst [39].

\subsubsection{Effect of $\mathrm{H}_{2} \mathrm{O}_{2}$ Concentration}

$\mathrm{H}_{2} \mathrm{O}_{2}$ and metal oxide nanoparticles have been used to increase the photocatalytic degradation rate of $\mathrm{MO}$ [40]. The addition of $\mathrm{H}_{2} \mathrm{O}_{2}$ in the presence of catalyst was studied [41]. Figure $6 \mathrm{~d}$ shows the effect of the $\mathrm{H}_{2} \mathrm{O}_{2}$ concentration on the photocatalytic degradation of MO. 


\subsection{Optimization for Photocatalytic Degradation of MO Using Response Surface Methodology (RSM)}

RSM was applied to predict the percentage efficiency (\%) of the photocatalytic degradation of $\mathrm{MO}$ using the $\mathrm{Gd}_{2} \mathrm{O}_{3}$-ZIF-8 nanocomposites photocatalyst under the variation of four parameters, namely, the $\mathrm{pH}$, catalyst dose $(\mathrm{g} / \mathrm{L})$, MO concentration $(\mathrm{mM})$, and $\mathrm{H}_{2} \mathrm{O}_{2}$ concentration $(\mathrm{mg} / \mathrm{L})$. We obtained the predicted degradation percentage using Design Expert 11 statistical software (Stat-Ease, Minneapolis, MN, USA) in Figure S3.

As shown in Table 3, the resulting photocatalytic degradation efficiency of MO fell in the range of 32.12 to $94.79 \%$. The quadratic polynomial regression model in Equation (4) was used to obtain the degradation percentage of MO:

$$
\text { Degradation }(\%)
$$

$$
\begin{gathered}
=64.46-14.04 X_{1}+5.39 X_{2}-10.71 X_{3}+9.51 X_{4}-3.36 X_{1} X_{2}-0.51 X_{1} X_{3}-4.24 X_{1} X_{4} \\
+1.87 X_{2} X_{3}+1.79 X_{2} X_{4}-1.04 X_{3} X_{4}+3.75 X_{1}^{2}-5.90 X_{2}^{2}+3.29 X_{3}^{2}-16.46 X_{4}^{2}
\end{gathered}
$$

where $X_{1}, X_{2}, X_{3}$, and $X_{4}$ represent the coded values of the $\mathrm{pH}$, photocatalyst dose, initial $\mathrm{MO}$ solution concentration, and $\mathrm{H}_{2} \mathrm{O}_{2}$ concentration, respectively. The accuracy of the model was verified by analysis of variance (ANOVA), and the results are presented in Table 4 . The fitness of the BBD model was obtained by applying the suitability equation to the quadratic polynomial model based on the experimental data in Table 4 [15]. The obtained experimental data were scattered very closely to the trend line of the predicted data, as shown in Figure 7 [36]. The statistical parameters evaluated were the value of $\mathrm{R}^{2}$, the lack of fit (LOF), the $p$ value, and the $F$ value [42]. A regression model with a $\mathrm{R}^{2}$ value greater than 0.9 is considered to have a high correlation between the experimental and predicted values [42]. In this study, the $\mathrm{R}^{2}$ correlation factor obtained was 0.9988 , indicating an excellent correlation and a satisfactory model for predicting the best conditions for $\mathrm{MO}$ degradation using the $\mathrm{Gd}_{2} \mathrm{O}_{3}$-ZIF-8 nanocomposites. The $p$ value is an indicator of the statistical significance and interaction ability of each variable, wherein variables with lower $p$ values have greater significance. In the present study, ANOVA for the regression model was highly significant because of the very small $p$ value $<0.0001$, and a correspondingly large $F$ value (710.13) was obtained. The lack of fit value obtained for the $F$ value was 2.02 and had a larger $p$ value $(0.3762)>0.05$, indicating that the lack of fit was not significant [42-45]. Therefore, the regression model is reliable for predicting the effects of variables affecting the photocatalytic degradation of $\mathrm{MO}$ by the $\mathrm{Gd}_{2} \mathrm{O}_{3}$-ZIF- 8 nanocomposites and can be used to direct the design space.

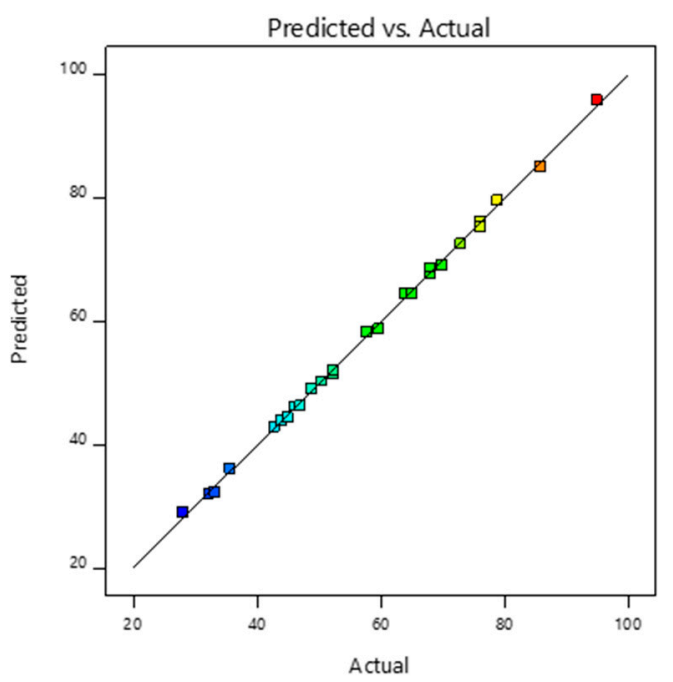

Figure 7. Plot of the experimental and predicted response obtained for photocatalytic degradation of $\mathrm{MO}$ using $\mathrm{Gd}_{2} \mathrm{O}_{3}-\mathrm{ZIF}-8$ nanocomposites. 
Table 4. ANOVA of the BBD quadratic polynomial model for photocatalytic degradation of MO using $\mathrm{Gd}_{2} \mathrm{O}_{3}$-ZIF-8 nanocomposites.

\begin{tabular}{lllllll}
\hline \multicolumn{1}{c}{ Source } & $\begin{array}{l}\text { Sum of } \\
\text { Squares }\end{array}$ & $\boldsymbol{D f}$ & $\begin{array}{c}\text { Mean } \\
\text { Square }\end{array}$ & $\boldsymbol{F}$ Value & $\boldsymbol{p}$ Value & \\
\hline Model & 7655.69 & 14 & 546.84 & 710.13 & $<0.0001$ & Significant \\
$X_{1}$ & 2364.71 & 1 & 2364.71 & 3070.86 & $<0.0001$ & - \\
$X_{2}$ & 348.02 & 1 & 348.02 & 451.95 & $<0.0001$ & - \\
$X_{3}$ & 1375.69 & 1 & 1375.69 & 1786.50 & $<0.0001$ & - \\
$X_{4}$ & 1085.62 & 1 & 1085.62 & 1409.81 & $<0.0001$ & - \\
$X_{1} X_{2}$ & 45.10 & 1 & 45.10 & 58.56 & $<0.0001$ & - \\
$X_{1} X_{3}$ & 1.03 & 1 & 1.03 & 1.34 & 0.2702 & - \\
$X_{1} X_{4}$ & 71.86 & 1 & 71.86 & 93.32 & $<0.0001$ & - \\
$X_{2} X_{3}$ & 13.96 & 1 & 13.96 & 18.13 & 0.0011 & - \\
$X_{2} X_{4}$ & 12.79 & 1 & 12.79 & 16.61 & 0.0015 & - \\
$X_{3} X_{4}$ & 4.31 & 1 & 4.31 & 5.59 & 0.0357 & - \\
$X_{1}^{2}$ & 75.00 & 1 & 75.00 & 97.40 & $<0.0001$ & - \\
$X_{2}{ }^{2}$ & 185.88 & 1 & 185.88 & 241.38 & $<0.0001$ & - \\
$X_{3}{ }^{2}$ & 57.79 & 1 & 57.79 & 75.05 & $<0.0001$ & - \\
$X_{4}{ }^{2}$ & 1445.08 & 1 & 1445.08 & 1876.62 & $<0.0001$ & - \\
Residual & 9.24 & 12 & 0.7700 & - & - & - \\
Lack of Fit & 8.41 & 10 & 0.8408 & 2.02 & 0.3762 & Insignificant \\
Pure Error & 0.8323 & 2 & 0.4162 & - & - & - \\
Total & 7664.94 & 26 & - & - & - & - \\
\hline
\end{tabular}

$\mathrm{R}^{2}=0.9988$; adequate precision $=102.0570$.

The linear and quadratic terms that affect the photocatalytic degradation of $\mathrm{MO}$ were highly significant, with $p<0.0001$. Meanwhile, the interaction terms $X_{1} X_{2}$ and $X_{1} X_{4}$ were significant, with $p<0.0001$ (Table 4) [16]. However, the interaction term $X_{1} X_{3}$ was not significant within the range assessed in this study. In Figure 6, the influence of a single factor on the degradation of $\mathrm{MO}$ was evaluated when all the other factors were maintained at the constant values for which the coded values of these factors are zero and lie between their low and high values. The $\mathrm{pH}$ and $\mathrm{MO}$ concentration negatively affected the photocatalytic degradation of MO. The efficiency of the photocatalytic degradation of MO decreased as the $\mathrm{pH}$ of the solution increased from 3 to $7 .\left(X_{2}\right)$ and $\left(X_{4}\right)$ showed a positive effect on the photocatalytic degradation. The photocatalytic degradation of $\mathrm{MO}$ using the $\mathrm{Gd}_{2} \mathrm{O}_{3}$-ZIF-8 nanocomposites showed an upward trend with an increase in $\left(\mathrm{X}_{2}\right)$ and $\left(X_{4}\right)$. This increase is attributed to the increase in the number of active sites on the photocatalyst surface.

Figure $8 \mathrm{a}, \mathrm{b}$ show the interaction between the $\mathrm{pH}$ and photocatalyst dose at constant concentrations of $\mathrm{MO}$ and $\mathrm{H}_{2} \mathrm{O}_{2}$. Figure $8 \mathrm{c}$, d show the interaction between the $\mathrm{pH}$ and concentration of $\mathrm{H}_{2} \mathrm{O}_{2}$ at constant concentrations of $\mathrm{MO}$ and the photocatalyst. The results clearly show that the effect of $\mathrm{pH}$ was more significant than those of the other factors in the photocatalytic degradation of $\mathrm{MO}$, which could be attributed to the surface charge of the photocatalyst and the structural change of $\mathrm{MO}$ under different solution $\mathrm{pH}$ values. In runs 1 and 23, the degradation efficiency increased from $46.93 \%$ to $75.89 \%$ when the solution $\mathrm{pH}$ decreased from 7 to 3 . The photocatalytic degradation efficiency increased from 43.85 to $57.62 \%$ when the catalyst dose increased from $0.1 \mathrm{~g} / \mathrm{L}$ in run 8 to $0.5 \mathrm{~g} / \mathrm{L}$ in run 15. In addition, when the concentration of $\mathrm{H}_{2} \mathrm{O}_{2}$ increased from $111 \mathrm{mg} / \mathrm{L}$ to $555 \mathrm{mg} / \mathrm{L}$, the degradation efficiency increased from $32.12 \%$ to $48.63 \%$. Meanwhile, the interaction between both factors was highly significant $(p<0.0001)$. This suggests that a high percentage of $\mathrm{MO}$ degradation can be achieved with a high $\mathrm{H}_{2} \mathrm{O}_{2}$ concentration as well as a low $\mathrm{pH}$, which can be seen from the direct proportionality between the $\mathrm{H}_{2} \mathrm{O}_{2}$ concentration and the $\mathrm{pH}$ in Figure 8c,d. In addition, a high concentration of $\mathrm{H}_{2} \mathrm{O}_{2}$ and photocatalyst at low $\mathrm{pH}$ increased the availability of local electrons on the surface of the photocatalyst, thereby increasing the photocatalytic degradation rate. In general, the photocatalytic degradation of $\mathrm{MO}$ increased when a larger amount of photocatalyst was 
used in the reaction because the number of active sites increased when there was a high surface-to-volume ratio. In addition, the abundant availability of active sites allowed $\cdot \mathrm{OH}$ radicals and $\mathrm{MO}$ to be easily adsorbed onto the surface of the photocatalyst followed by the fast exchange of electrons between the reactants. As a result, MO degradation occurred rapidly. However, a slight decline in the photocatalytic degradation percentage was observed when the amount of photocatalyst used exceeded the optimal dosage.

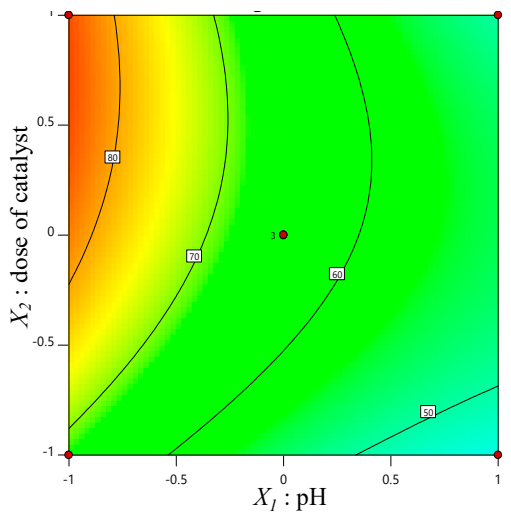

(a)

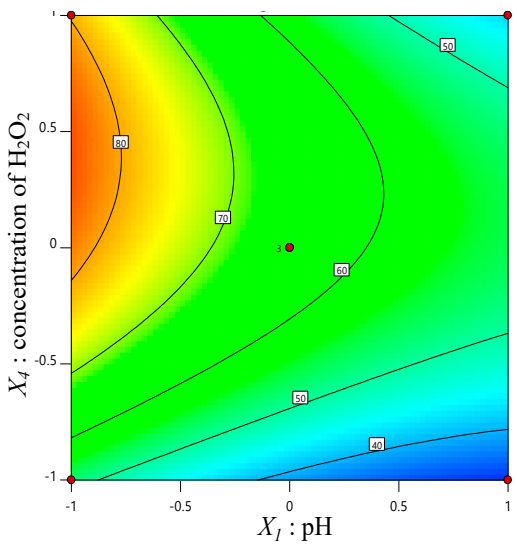

(c)

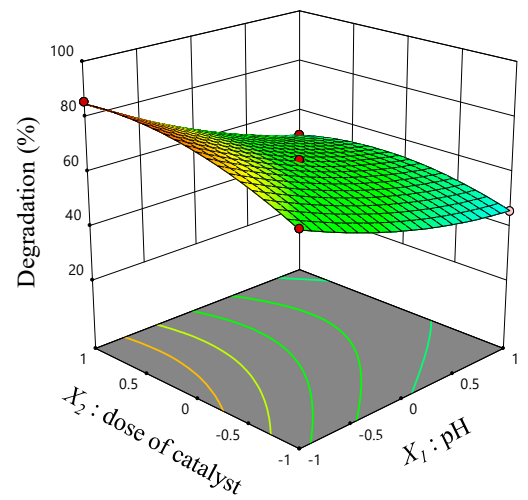

(b)

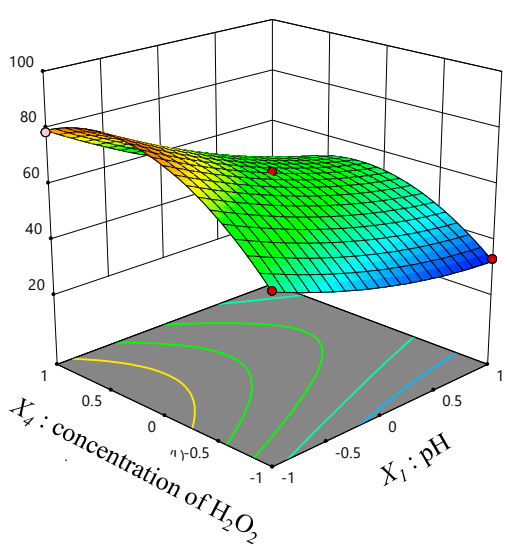

(d)

Figure 8. Response surface graphs and plots for photocatalytic degradation (\%): (a,b) between $\mathrm{pH}$ and catalyst dose with the remaining factors fixed at $0.084 \mathrm{mM} \mathrm{MO}$ concentration and $333 \mathrm{mg} / \mathrm{L}$ $\mathrm{H}_{2} \mathrm{O}_{2}$ concentration, and (c,d) between $\mathrm{pH}$ and $\mathrm{H}_{2} \mathrm{O}_{2}$ concentration with the remaining factors fixed at $0.3 \mathrm{~g} / \mathrm{L}$ catalyst dose and $0.084 \mathrm{mM} \mathrm{MO}$ concentration.

\subsection{Optimum Condition and Model Verification}

Within the experimental conditions of the parameters we used, the RSM method was to determine the optimal condition for the photocatalytic degradation of MO. Therefore, we have limited experimental conditions for the following: The $\mathrm{pH}$ ranges from 3 to 7 , the dose of catalyst ranges from $0.1 \mathrm{~g} / \mathrm{L}$ to $0.5 \mathrm{~g} / \mathrm{L}$, the concentration of $\mathrm{MO}$ ranges from $0.0630 \mathrm{mM}$ to $0.1050 \mathrm{mM}$, and the concentration of $\mathrm{H}_{2} \mathrm{O}_{2}$ ranges from $111 \mathrm{mg} / \mathrm{L}$ to $555 \mathrm{mg} / \mathrm{L}$.

The optimization function in Design Expert 11.0 was used to obtain the optimum conditions for the photocatalytic degradation of MO under four constraints: (1) The maximum photocatalytic degradation percentage was $97.24 \%$ at the initial $\mathrm{pH}$ of 3.3 , photocatalyst dose of $0.4 \mathrm{~g} / \mathrm{L}$, MO concentration of $0.0635 \mathrm{mM}$, and $\mathrm{H}_{2} \mathrm{O}_{2}$ concentration of $431 \mathrm{mg} / \mathrm{L}$. The experiment showed a photocatalytic degradation percentage of $98.05 \%$ under the optimum conditions compared with the photocatalytic degradation of $97.24 \%$ obtained from the regression model. In addition, the conditions for obtaining the highest 
MO photocatalytic degradation percentage at (2) the minimum weight of photocatalyst, (3) the minimum volume of $\mathrm{H}_{2} \mathrm{O}_{2}$, and (4) neutral $\mathrm{pH}$ are also listed in Table 5 [45]. The results show that the experimental design was effectively applied for optimizing the photocatalytic degradation of MO.

Table 5. The obtained optimum conditions for the photocatalytic degradation of $\mathrm{MO}$ using $\mathrm{Gd}_{2} \mathrm{O}_{3}$ ZIF-8 nanocomposites.

\begin{tabular}{cccccccc}
\hline NO. & $\boldsymbol{X}_{\mathbf{1}}$ & $\boldsymbol{X}_{\mathbf{2}}$ & $\boldsymbol{X}_{\mathbf{3}}$ & $\boldsymbol{X}_{\mathbf{4}}$ & Experimental & Predicted & Deviation (\%) \\
\hline 1. & 3.3 & 0.40 & 0.0635 & 431 & 98.05 & 97.24 & 0.82 \\
2. & 3.0 & 0.10 & 0.0630 & 419 & 85.22 & 85.53 & 0.36 \\
3. & 3.0 & 0.40 & 0.0630 & 203 & 83.10 & 83.63 & 0.64 \\
4. & 7.0 & 0.39 & 0.0635 & 375 & 68.22 & 69.29 & 1.57 \\
\hline
\end{tabular}

\section{Materials and Methods}

\subsection{Materials}

Gadolinium nitrate hexahydrate $\left(\mathrm{Gd}\left(\mathrm{NO}_{3}\right)_{3} \cdot 6 \mathrm{H}_{2} \mathrm{O}\right)$, ethylamine $\left(\mathrm{C}_{2} \mathrm{H}_{5} \mathrm{NH}_{2}\right)$, zinc acetate dihydrate $\left(\mathrm{Zn}\left(\mathrm{CH}_{3} \mathrm{COO}\right)_{2} \cdot 2 \mathrm{H}_{2} \mathrm{O}\right)$, 2-methylimidazole $\left(\mathrm{CH}_{2} \mathrm{C}_{3} \mathrm{H}_{3} \mathrm{~N}_{2}\right)$, polyvinylpyrrolidone $\left(\left(\mathrm{C}_{6} \mathrm{H}_{9} \mathrm{NO}\right)_{n}\right.$, average mol wt. 10,000 , PVP), methyl orange $\left(\mathrm{C}_{14} \mathrm{H}_{14} \mathrm{~N}_{3} \mathrm{NaO}_{3} \mathrm{~S}, \mathrm{MO}\right)$, and hydrogen peroxide $\left(\mathrm{H}_{2} \mathrm{O}_{2}, 30 \%, w / w\right)$ were purchased from Yakuri Pure Chemicals (Tokyo, Japan), Sigma-Aldrich (St. Louis, MO, USA), Merck (KGaA, Darmstadt, Germany), and Daejung Chemicals (Siheung, Korea). All the chemicals were used without further purification.

\subsection{Measurement Methods}

The structure pattern and average crystallite size of $\mathrm{Gd}_{2} \mathrm{O}_{3}-\mathrm{ZIF}-8$ nanocomposites were investigated using an X-ray diffractometer (Bruker, D8 ADVANCE, Karlsruhe, Germany) with a $\mathrm{Cu} \mathrm{K} \alpha$ radiation source $(0.1504 \mathrm{~nm})$. The morphology of the synthesized $\mathrm{Gd}_{2} \mathrm{O}_{3}$-ZIF8 nanocomposite photocatalyst was observed at an accelerating voltage of $10-20 \mathrm{kV}$ using scanning electron microscopy (SEM, JEOL Ltd., JSM-6510, Tokyo, Japan). The vibrational states of the synthesized $\mathrm{Gd}_{2} \mathrm{O}_{3}$-ZIF-8 nanocomposites were investigated by Raman spectroscopy (532 nm excitation, BWTEK i-Raman Plus, Newark, DE, USA). Photocatalytic degradation of the MO dye was carried out using a UV lamp (Light intensity is $4 \mathrm{~W}, 254 \mathrm{~nm}$ ) and was confirmed by UV-vis spectroscopy (Shimazu UV-1601 PC, Tokyo, Japan). The color of MO dye solution was observed using a color spectrophotometer (Colormate, Scinco, Seoul, Korea).

\subsubsection{Preparation of $\mathrm{Gd}_{2} \mathrm{O}_{3}$ Nanowires}

$\mathrm{Gd}_{2} \mathrm{O}_{3}$ nanowires were synthesized using the following hydrothermal procedure: $0.9 \mathrm{~g}$ of $\mathrm{Gd}\left(\mathrm{NO}_{3}\right)_{3} \cdot 6 \mathrm{H}_{2} \mathrm{O}$ was dissolved in $25 \mathrm{~mL}$ of deionized water. $0.5 \mathrm{~mL}$ of $\mathrm{C}_{2} \mathrm{H}_{5} \mathrm{NH}_{2}$ was then added slowly to the $\mathrm{Gd}\left(\mathrm{NO}_{3}\right)_{3}$ aqueous solution under vigorous stirring. The obtained white precipitate solution was heated for $12 \mathrm{~h}$ in an oven at $120^{\circ} \mathrm{C}$. The mixture was centrifuged several times after cooling and washed with deionized water to obtain gadolinium hydroxide. The gadolinium hydroxide was dried at $80{ }^{\circ} \mathrm{C}$ in an oven and then annealed in an electric furnace at $700{ }^{\circ} \mathrm{C}$ for $4 \mathrm{~h}$ in an $\mathrm{Ar}$ atmosphere to obtain $\mathrm{Gd}_{2} \mathrm{O}_{3}$ [22].

\subsubsection{Ultrasound Assisted Synthesis of $\mathrm{Gd}_{2} \mathrm{O}_{3}$-ZIF-8 Nanocomposites}

$\mathrm{Gd}_{2} \mathrm{O}_{3}$ nanowires $(10 \mathrm{mg})$, PVP $(0.1 \mathrm{~g})$, and 2-methylimidazole $(0.263 \mathrm{~g})$ were dispersed in $20 \mathrm{~mL}$ of methanol with stirring for $30 \mathrm{~min}$. $20 \mathrm{~mL}$ of a methanol solution of $\mathrm{Zn}\left(\mathrm{CH}_{3} \mathrm{COO}\right)_{2} \cdot 2 \mathrm{H}_{2} \mathrm{O}(0.146 \mathrm{~g})$ was then added to the solution. The solution was sonicated for $30 \mathrm{~min}$ at $750 \mathrm{~W}$. The precipitate was washed several times with methanol and collected after centrifugation to obtain the $\mathrm{Gd}_{2} \mathrm{O}_{3}$-ZIF-8 nanocomposites [46]. 


\subsubsection{Photocatalytic Activity of $\mathrm{MO}$ Degradation using $\mathrm{Gd}_{2} \mathrm{O}_{3}$-ZIF- 8 Nanocomposites}

The photocatalytic degradation of $\mathrm{MO}$ by the $\mathrm{Gd}_{2} \mathrm{O}_{3}-\mathrm{ZIF}-8$ nanocomposites was performed in an aqueous MO dye solution under UV irradiation at $254 \mathrm{~nm}$.

The initial $\mathrm{pH}$ values were adjusted to 3, 5, and 7 using $1 \mathrm{M}$ aqueous $\mathrm{HCl}$ solution. The photocatalyst was added to the prepared MO solution and kept under constant stirring in the dark for adsorption. After adsorption-desorption equilibrium was reached between the $\mathrm{MO}$ dye and the catalyst in the solution for $30 \mathrm{~min}$, the solution was irradiated under UV light at $254 \mathrm{~nm}$ with regular intervals, after which the photocatalytic degradation of MO was observed by UV-vis spectrophotometry. The photocatalytic degradation efficiency was measured using the following equation (Equation (5)) [21,47]:

$$
\text { Photocatalytic degradation efficiency }(\%)=\left(C_{0}-C\right) / C_{0} \times 100
$$

where $C_{0}$ is the initial $\mathrm{MO}$ concentration after adsorption-desorption equilibrium has been reached under dark conditions $(t=0)$, and $C$ is the $\mathrm{MO}$ concentration after $40 \mathrm{~min}$. The values for the photocatalytic degradation of MO are shown in Table 2.

\subsubsection{Evaluation of Color Change during Photocatalytic Degradation of MO}

The CIELAB method was used to determine the color parameters $L, a$, and $b . L$ indicates the lightness, and $a$ and $b$ are the chromaticity coordinates. The $a$ parameter represents the red $(+)$ to green $(-)$ components. The $b$ parameter represents the yellow $(+)$ to blue $(-)$ components. $L$ can vary from white (100) to black (0) [48]. The colors of the initial and final solutions were measured using a color spectrophotometer. The total color change $(\Delta E)$ for each solution was calculated as follows:

$$
\begin{gathered}
\Delta a=a_{0}-a_{t} \\
\Delta b=b_{0}-b_{t} \\
\Delta L=L_{0}-L_{t} \\
\Delta E=\left(\Delta a^{2}+\Delta b^{2}+\Delta L^{2}\right)^{1 / 2}
\end{gathered}
$$

where $a_{0}, b_{0}$, and $L_{0}$ are the initial color parameters; $a_{t}, b_{t}$, and $L_{t}$ the final parameters at the reaction time $\mathrm{t}(\mathrm{min}) ;$ and $\Delta a, \Delta b$, and $\Delta L$ are the differences between the initial and final parameter values $[34,35]$.

\subsubsection{Experimental Design with RSM}

The experimental design was based on the Box-Behnken design (BBD) with four factors at three levels. Table 1 shows the independent variables, experimental ranges, and coded levels of the tested variables in the BBD. The initial $\mathrm{pH}\left(X_{1}\right)$, dose of catalyst $\left(X_{2}\right)$, concentration of $\mathrm{MO}\left(X_{3}\right)$, and concentration of $\mathrm{H}_{2} \mathrm{O}_{2}\left(X_{4}\right)$ were selected as the independent variables. The predicted photocatalytic degradation efficiency of $\mathrm{MO}(Y)$ was used as the dependent variable. A quadratic polynomial equation (Equation (10)) was used to fit the response variables [20,45]:

$$
Y=\beta_{0}+\sum_{i=1}^{k} \beta_{i} X_{i}+\sum_{i=1}^{k} \beta_{i i} X_{i}^{2}+\sum_{i=j}^{k-1} \sum_{j=i+1}^{k} \beta_{i j} X_{i} X_{j}
$$

where $\beta_{0}$ is a constant coefficient, $\beta_{i}$ are the linear interaction coefficients, $\beta_{i i}$ are the quadratic interaction coefficients, $\beta_{i j}$ are the cross-factor interaction coefficients, $k$ is the number of factors investigated in the experiment, and $X_{i}$, and $X_{j}$ are independent variables [45]. In the analysis of variance (ANOVA), the significance and suitability of the model were assessed using the lack of fit (LOF), $F$ value, $p$ value, and coefficient of determination $\left(\mathrm{R}^{2}\right)$. Surface plots (3D) and contour plots (2D) of MO photocatalytic degradation efficiency (\%) were employed to demonstrate the effect of two interaction variables on the response (\% degradation) based on the model Equation (10). 


\section{Conclusions}

In this study, $\mathrm{Gd}_{2} \mathrm{O}_{3}$-ZIF-8 nanocomposites were successfully prepared using an ultrasound-assisted synthesis method and characterized by XRD, Raman spectroscopy, SEM, and UV-vis spectroscopy. The photocatalytic degradation of $\mathrm{MO}$ using $\mathrm{Gd}_{2} \mathrm{O}_{3}$ ZIF-8 nanocomposites as catalyst under various conditions was studied in detail. The color changes between the initial and final $L a b$ values were confirmed in the coordinate diagram. The optimization of the $\mathrm{MO}$ photocatalytic degradation process was studied using response surface methodology based on the Box-Behnken design. The proposed regression model was highly reliable. Under optimal conditions $(\mathrm{pH} 3.3,431 \mathrm{mg} / \mathrm{L}$ of $\mathrm{H}_{2} \mathrm{O}_{2}, 0.0635 \mathrm{mM}$ of $\mathrm{MO}$, and $0.4 \mathrm{~g} / \mathrm{L}$ of photocatalyst), the photocatalytic degradation percentage of $\mathrm{MO}$ was $98.05 \%$ after $40 \mathrm{~min}$. The photocatalytic degradation of $\mathrm{MO}$ using $\mathrm{Gd}_{2} \mathrm{O}_{3}$-ZIF-8 nanocomposites was found to follow the pseudo-first-order kinetics rate law.

Supplementary Materials: The following are available online at https:/ /www.mdpi.com/article/ 10.3390/catal11091022/s1, Figure S1: (a) UV-vis spectrum and (b) Tauc's plot for the bandgap energy of the Gd2O3-ZIF-8 nanocomposites, Figure S2: Kinetics study for photocatalytic degradation of MO (a) first-order kinetic model and (b) second-order kinetic model, Figure S3: Predicted photocatalytic degradation percentage of MO using Design Expert 11 statistical software (Stat-Ease, Minneapolis, MN, USA).

Author Contributions: Conceptualization, W.-B.K.; methodology, S.-G.J., J.-W.K.; writing—original draft preparation, S.-G.J., J.-W.K.; writing—review and editing, W.-B.K. All authors have read and agreed to the published version of the manuscript.

Funding: This research was supported by research foundation of Sahmyook University.

Data Availability Statement: In the data presented in this study are available in article.

Conflicts of Interest: The author declare that they have no conflict of interest.

\section{References}

1. Ghiasi, E.; Azim, M. Removal of various textile dyes using $\mathrm{LaMn}(\mathrm{Fe}) \mathrm{O}_{3}$ and $\mathrm{LaFeMn}_{0.5} \mathrm{O}_{3}$ nanoperovskites; RSM optimization, isotherms and kinetics studies. J. Inorg. Organomet. Ploym. Mater. 2020, 30, 2789-2804. [CrossRef]

2. Zhang, M.; Shang, Q.; Wan, Y.; Cheng, Q.; Liao, G.; Pan, Z. Self-template synthesis of double-shell TiO ${ }_{2} @$ ZIF-8 hollow nanospheres via sonocrystallization with enhanced photocatalytic activities in hydrogen generation. Appl. Catal. B Environ. 2019, 241, 149-158. [CrossRef]

3. Wang, Y.; Zhou, S.; Zhao, G.; Li, C.; Liu, L.; Jiao, F. Fabrication of SnWO $/$ ZnFe-layered double hydroxide composites with enhanced photocatalytic degradation of methyl orange. J. Mater. Sci. Mater. Electron. 2020, 31, 12269-12281. [CrossRef]

4. Dhanalakshmi, S.; Kumar, P.S.; Karuthapandian, S.; Muthuraj, V.; Prithivikumaran, N. Design of $\mathrm{Gd}_{2} \mathrm{O}_{3}$ nanorods: A challenging photocatalyst for the degradation of neurotoxicity chloramphenicol drug. J. Mater. Sci. Mater. Electron. 2019, 30, $3744-3752$. [CrossRef]

5. Surendra, T.V.; Mohana, R.S.; Khan, M.R. Biogenic approach to synthesize rod shaped $\mathrm{Gd}_{2} \mathrm{O}_{3}$ nanoparticles and its optimization using response surface methodology-Box-Behnken design model. Biotechnol. Prog. 2019, 3, e2823-e2834.

6. Liu, Y.; Liu, Z.; Huang, D.; Cheng, M.; Zeng, G.; Lai, C.; Zhang, C.; Zhou, C.; Wang, W.; Jiang, D.; et al. Metal or metal-containing nanoparticle@ MOF nanocomposites as a promising type of photocatalyst. Coord. Chem. Rev. 2019, 388, 63-78. [CrossRef]

7. Jing, H.P.; Wang, C.C.; Zhang, Y.W.; Wang, P.; Li, R. Photocatalytic degradation of methylene blue in ZIF-8. RSC Adv. 2014, 4, 54454-54462. [CrossRef]

8. Qi, X.; Shang, F.; Wang, T.; Ma, Y.; Yan, Y. In situ coupling of $\mathrm{TiO}_{2}(\mathrm{~B})$ and ZIF-8 with enhanced photocatalytic activity via effective defect. CrystEngComm 2020, 22, 4250-4259. [CrossRef]

9. Chen, Y.; Li, J.; Yue, G.; Luo, X. Novel Ag@nitrogen-doped porous carbon composite with high electrochemical performance as anode materials for lithium-ion batteries. Nano-Micro Lett. 2017, 9, 32-42. [CrossRef] [PubMed]

10. Faraji, A.; Mehrdadi, N.; Mahmoodi, N.M.; Pardakhti, A. Enhanced photocatalytic activity by synergic action of ZIF-8 and $\mathrm{NiFe}_{2} \mathrm{O}_{4}$ under visible light irradiation. J. Mol. Struct. 2021, 1223, 129028. [CrossRef]

11. Li, R.; Li, W.; Jin, C.; He, Q.; Wang, Y. Fabrication of ZIF-8@ TiO 2 micron composite via hydrothermal method with enhanced absorption and photocatalytic activities in tetracycline degradation. J. Alloys Compd. 2020, 825, 154008-154017. [CrossRef]

12. Zeng, X.; Huang, L.; Wang, C.; Wang, J.; Li, J.; Luo, X. Sonocrystallization of ZIF-8 on electrostatic spinning TiO 2 nanofibers surface with enhanced photocatalysis property through synergistic effect. ACS Appl. Mater. Inter. 2016, 8, 20274-20282. [CrossRef]

13. Zheng, H.B.; Wu, D.; Wang, Y.L.; Liu, X.P.; Gao, P.Z.; Liu, W.; Rebrov, E.V. One-step synthesis of ZIF-8/ZnO composites based on coordination defect strategy and its derivatives for photocatalysis. J. Alloys Compd. 2020, 838, 155219-155229. [CrossRef] 
14. Chandra, R.; Singh, V.; Tomar, S.; Nath, M. Multi-core-shell composite $\mathrm{SnO}_{2}$ NPs@ZIF-8: Potential antiviral agent and effective photocatalyst for waste-water treatment. Environ. Sci. Pollut. Res. 2019, 26, 23346-23358. [CrossRef]

15. Garcia, B.B.; Lourinho, G.; Romano, P.; Brito, P.S.D. Photocatalytic degradation of swine wastewater on aqueous TiO ${ }_{2}$ suspensions: Optimization and modeling via Box-Behnken design. Heliyon 2020, 6, e03293-e03300. [CrossRef] [PubMed]

16. Gholamnia, R.; Abtahi, M.; Saeedi, R.; Khaloo, S.S. Synthesis and characterization of a new magnetic adsorbent for removal of 4-nitrophenol: Application of response surface methodology. Water Sci. Technol. 2019, 80, 1430-1442. [CrossRef]

17. Azimi, F.; Nabizadeh, R.; Hassanvand, M.S.; Rastkari, N.; Nazmara, S.; Naddafi, K. Photochemical degradation of toluene in gas-phase under $\mathrm{UV} /$ visible light graphene oxide- $\mathrm{TiO}_{2}$ nanocomposite: Influential operating factors, optimization, and modeling. J. Environ. Health Sci. 2019, 17, 671-683. [CrossRef]

18. Chawla, P.; Sharma, S.K.; Toor, A.P. Optimization and modeling of UV- $\mathrm{TiO}_{2}$ mediated photocatalytic degradation of golden yellow dye through response surface methodology. Chem. Eng. Commun. 2019, 206, 1123-1138. [CrossRef]

19. Mortazavian, S.; Saber, A.; James, D.E. Optimization of photocatalytic degradation of Acid Blue 113 and Acid Red 88 textile dyes in a UV-C/ $\mathrm{TiO}_{2}$ suspension system: Application of response surface methodology (RSM). Catalysts 2019, 9, 360. [CrossRef]

20. Ghadiri, S.K.; Alidadi, H.; Tavakkoli, N.N.; Javid, A.; Roudbari, A.; Talebi, S.S.; Rezania, S. Valorization of biomass into aminefunctionalized bio graphene for efficient ciprofloxacin adsorption in water-modeling and optimization study. PLoS ONE 2020, 15, e0231045-e0231063. [CrossRef]

21. Nam, S.N.; Cho, H.; Han, J.; Her, N.; Yoon, J. Photocatalytic degradation of acesulfame K: Optimization using the Box-Behnken design (BBD). Process Saf. Environ. Prot. 2018, 113, 10-21. [CrossRef]

22. Kang, J.G.; Min, B.K.; Sohn, Y. Synthesis and characterization of $\mathrm{Gd}(\mathrm{OH})_{3}$ and $\mathrm{Gd}_{2} \mathrm{O}_{3}$ nanorods. Ceram. Int. 2015, 41, 1243-1248. [CrossRef]

23. Paul, A.; Vyas, G.; Paul, P.; Srivastava, D.N. Gold-nanoparticle-encapsulated ZIF-8 for a mediator-free enzymatic glucose sensor by amperometry. ACS Appl. Nano Mater. 2018, 1, 3600-3607. [CrossRef]

24. Zhou, K.; Mousavi, B.; Luo, Z.; Phatanasri, S.; Chaemchuen, S.; Verpoort, F. Characterization and properties of Zn/Co zeolitic imidazolate frameworks vs. ZIF-8 and ZIF-67. J. Mater. Chem. A 2017, 5, 952-957. [CrossRef]

25. Pinheiro, D.; Devi, K.S.; Jose, A.; Karthik, K.; Sugunan, S.; Mohan, M.K. Experimental design for optimization of 4-nitrophenol reduction by green synthesized $\mathrm{CeO}_{2} / \mathrm{g}-\mathrm{C}_{3} \mathrm{~N}_{4} / \mathrm{Ag}$ catalyst using response surface methodology. J. Rare Earths 2020, 38, $1171-1177$. [CrossRef]

26. Jeon, S.; Ko, J.W.; Ko, W.B. Synthesis of $\mathrm{Gd}_{2} \mathrm{O}_{3}$ Nanoparticles and Their Photocatalytic Activity for Degradation of Azo Dyes. Catalysts 2021, 11, 742. [CrossRef]

27. Tanaka, S.; Fujita, K.; Miyake, Y.; Miyamoto, M.; Hasegawa, Y.; Makino, T.; Denayer, J.F. Adsorption and diffusion phenomena in crystal size engineered ZIF-8 MOF. J. Phys. Chem. C 2015, 119, 28430-28439. [CrossRef]

28. Kumari, G.; Jayaramulu, K.; Maji, T.K.; Narayana, C. Temperature induced structural transformations and gas adsorption in the zeolitic imidazolate framework ZIF-8: A Raman study. J. Phys. Chem. A 2013, 117, 11006-11012. [CrossRef] [PubMed]

29. Liu, J.; Sun, Y.; Li, Z. Ag loaded flower-like $\mathrm{BaTiO}_{3}$ nanotube arrays: Fabrication and enhanced photocatalytic property. CrystEngComm 2012, 14, 1473-1478. [CrossRef]

30. Chiu, Y.H.; Chang, T.F.M.; Chen, C.Y.; Sone, M.; Hsu, Y.J. Mechanistic insights into photodegradation of organic dyes using heterostructure photocatalysts. Catalysts 2019, 9, 430. [CrossRef]

31. Wojnárovits, L.; Pálfi, T.; Takács, E. Kinetics and mechanism of azo dye destruction in advanced oxidation processes. Radiat. Phys. Chem. 2007, 76, 1497-1501. [CrossRef]

32. Hsiao, P.H.; Timjan, S.; Kuo, K.Y.; Juan, J.C.; Chen, C.Y. Optical management of CQD/AgNP@ SiNW arrays with highly efficient capability of dye degradation. Catalysts 2021, 11, 399. [CrossRef]

33. Hsiao, P.H.; Li, T.C.; Chen, C.Y. ZnO/ $\mathrm{Cu}_{2} \mathrm{O} / \mathrm{Si}$ nanowire arrays as ternary heterostructure-based photocatalysts with enhanced photodegradation performances. Nanoscale Res. Lett. 2019, 14, 244. [CrossRef] [PubMed]

34. Polleto, M. Comparative study of wood flour photodegradation of two wood species submitted to artificial weathering. Maderas Cienc. Tecnol. 2017, 19, 141-148. [CrossRef]

35. Baysal, E.; Degirmentepe, S.; Simsek, H. Some surface properties of thermally modified scots pine after artificial weathering. Maderas Cienc. Tecnol. 2014, 16, 355-364. [CrossRef]

36. Lin, Y.P.; Mehrvar, M. Photocatalytic treatment of an actual confectionery wastewater using $\mathrm{Ag} / \mathrm{TiO}_{2} / \mathrm{Fe}_{2} \mathrm{O}_{3}$ : Optimization of photocatalytic reactions using surface response methodology. Catalysts 2018, 8, 409. [CrossRef]

37. Sakthivel, S.; Neppolian, B.; Shankar, M.V.; Arabindoo, B.; Palanichamy, M.; Murugesan, V. Solar photocatalytic degradation of azo dye: Comparison of photocatalytic efficiency of $\mathrm{ZnO}$ and $\mathrm{TiO}_{2}$. Sol. Energy Mater. Sol. Cells 2003, 77, 65-82. [CrossRef]

38. Hosseini, S.A.; Saeedi, R. Photocatalytic Degradation of Methyl Orange on $\mathrm{Bi}_{2} \mathrm{O}_{3}$ and $\mathrm{Ag}_{2} \mathrm{O}_{-} \mathrm{Bi}_{2} \mathrm{O}_{3}$ Nano Photocatalysts. Bull. Chem. React. Eng. Catal. 2017, 12, 96-105. [CrossRef]

39. Ghavami, M.; Mohammadi, R.; Koohi, M.; Kassaee, M.Z. Visible light photocatalytic activity of reduced graphene oxide synergistically enhanced by successive inclusion of $\gamma-\mathrm{Fe}_{2} \mathrm{O}_{3}, \mathrm{TiO}_{2}$, and Ag nanoparticles. Mater. Sci. Semicond. Process 2014, 26, 69-78. [CrossRef]

40. Haji, S.; Benstaali, B.; Al-Bastaki, N. Degradation of methyl orange by UV/ $\mathrm{H}_{2} \mathrm{O}_{2}$ advanced oxidation process. Chem. Eng. Sci. 2011, 168, 134-139. [CrossRef] 
41. Elmolla, E.S.; Chaudhuri, M. Photocatalytic degradation of amoxicillin, ampicillin and cloxacillin antibiotics in aqueous solution using $\mathrm{UV} / \mathrm{TiO}_{2}$ and $\mathrm{UV} / \mathrm{H}_{2} \mathrm{O}_{2} / \mathrm{TiO}_{2}$ photocatalysis. Desalination 2010, 252, 46-52. [CrossRef]

42. Pang, Y.L.; Law, Z.X.; Lim, S.; Chan, Y.Y.; Shuit, S.H.; Chong, W.C.; Lai, C.W. Enhanced photocatalytic degradation of methyl orange by coconut shell-derived biochar composites under visible LED light irradiation. Environ. Sci. Pollut. Res. 2021, 28, 27457-27473. [CrossRef]

43. Sabour, M.R.; Amiri, A. Comparative study of ANN and RSM for simultaneous optimization of multiple targets in Fenton treatment of landfill leachate. Waste Manag. 2017, 65, 54-62. [CrossRef]

44. Doğdu, O.G.; Baldan, P.N.; Ökten, H.E.; Yalçuk, A. A box-behnken design (Bbd) optimization of the photocatalytic degradation of 2, 4-dichlorophenoxyacetic acid (2, 4-d) using $\mathrm{TiO}_{2} / \mathrm{H}_{2} \mathrm{O}_{2}$. Desalin. Water Treat. 2018, 123, 188-195.

45. Abd, R.N.F.; Shamsuddin, M. Catalytic reduction of 4-nitrophenol over biostabilized gold nanoparticles supported onto thioctic acid functionalized silica-coated magnetite nanoparticles and optimization using response surface methodology. Inorg. Nano-Metal Chem. 2020, 50, 489-500.

46. Fu, F.; Zheng, B.; Xie, L.H.; Du, H.; Du, S.; Dong, Z. Size-controllable synthesis of zeolitic imidazolate framework/carbon nanotube composites. Crystals 2018, 8, 367. [CrossRef]

47. Yan, S.C.; Li, Z.S.; Zou, Z.G. Photodegradation of rhodamine B and methyl orange over boron-doped g- $\mathrm{C}_{3} \mathrm{~N}_{4}$ under visible light irradiation. Langmuir 2010, 26, 3894-3901. [CrossRef]

48. Kurz, W.; Yetisen, A.K.; Kaito, M.V.; Fuchter, M.J.; Jakobi, M.; Elsner, M.; Koch, A.W. UV-Sensitive Wearable Devices for Colorimetric Monitoring of UV Exposure. Adv. Opt. Mater. 2020, 8, 1901969-1901977. [CrossRef] 